\title{
Diabetic patient assessment of chronic illness care using PACIC+
}

Maria Malliarou', Christina Desikou², Eleni Lahana ${ }^{3}$, Styliani Kotrotsiou³, Theodosios Paralikas³, Athanasios Nikolentzos ${ }^{4}$, Evangelia Kotrotsiou ${ }^{3}$ and Pavlos Sarafis ${ }^{5^{*}}$ (i)

\begin{abstract}
Background: The Patient Assessment of Chronic Illness Care plus is used in order to assess whether provided care is congruent with the Chronic Care Model, according to patients. The purpose of this study was to correlate PACIC+ and the revised 5As "ask, advise, agree, assist and arrange" scoring of a sample of DM patients, with their QoL, depressive symptomatology, demographic and disease characteristics, self-management behaviours of healthy eating and physical activity.
\end{abstract}

Methods: This is a cross-sectional study where data were collected between January and April 2018 by using three questionnaires (PACIC+, SF-36, CES-D) from a sample of 90 DM patients treated at a Public General Hospital of Central Greece. Anonymous self-completed questionnaires were used to collect the data. Data was processed in the Statistical Package for the Social Sciences (SPSS).

Results: The mean age of the participants with DM was 52.8 years ( $S D=21.2$ years), with cardiovascular disease and arterial hypertension scoring as the most frequently reporting chronic comorbidities. The healthcare received by DM patients has been correlated with their QoL. More specifically SF - 36 and PACIC+ scale scores showed a positive and low correlation in several subscales. The total score of PACIC+ scale as well as the Patient activation score were increased in higher scores of vitality $(p=0.034 \& p=0.028$ respectively), hence both scores correlate significantly with latter. In addition, Delivery System / Practice Design score was increased in higher scores of mental health $(p=0.01)$ and MCS $(p=0.03)$.

Conclusions: The shift from hospital care focusing on the disease to a more patient-oriented approach puts forward a dynamic holistic approach to chronic diseases and the reduction of their impact. Finding evidence-based and effective strategies to promote health, prevent and manage chronic diseases such as diabetes mellitus is deemed to be crucial and necessary. PACIC+, which is a tool of a patient-level assessment of CCM implementation, can be used by countries which intend to apply changes in the way their health systems provide chronic care and specifically wish to improve the quality of chronic disease care and the QoL of their patients.

Keywords: Chronic illness, Diabetes, Quality of life, Chronic care model, CES-D, SF-36

\footnotetext{
*Correspondence: pavlos.sarafis@cut.ac.cy

${ }^{5}$ Department of Nursing, Cyprus University of Technology, 30 Archbishop

Street, 3036 Limassol, Cyprus

Full list of author information is available at the end of the article
}

(c) The Author(s). 2020 Open Access This article is licensed under a Creative Commons Attribution 4.0 International License, which permits use, sharing, adaptation, distribution and reproduction in any medium or format, as long as you give appropriate credit to the original author(s) and the source, provide a link to the Creative Commons licence, and indicate if changes were made. The images or other third party material in this article are included in the article's Creative Commons licence, unless indicated otherwise in a credit line to the material. If material is not included in the article's Creative Commons licence and your intended use is not permitted by statutory regulation or exceeds the permitted use, you will need to obtain permission directly from the copyright holder. To view a copy of this licence, visit http://creativecommons.org/licenses/by/4.0/ The Creative Commons Public Domain Dedication waiver (http://creativecommons.org/publicdomain/zero/1.0/) applies to the data made available in this article, unless otherwise stated in a credit line to the data. 


\section{Background}

Diabetes mellitus (DM) is a group of metabolic disorders characterized by high blood sugar level over a prolonged period of time $[1,2]$. The most common forms of DM are Type I (absolute insulin deficiency due to destruction of insulin-producing $\beta$-cells) and Type II (secretion and/ or insulin action disorder). Other specific types of diabetes are rare specific cases of secondary presentation [3] of the disease and gestational diabetes that often subsides after childbirth.

The global diabetes prevalence in 2019 was estimated to be $9.3 \%$ (463 million people), rising to $10.2 \%$ (578 million) by 2030 and $10.9 \%$ (700 million) by 2045 [4]. Despite the limited available data on the prevalence of DM in Greece, relatively recent studies summarize the rate of drug-treated DM in 7\% [5].

The autogenous complications in the DM, apart from vital organs, burden the mental health and social life of the sufferers and their relatives [6], causing further difficulties in achieving the goals and quality of their lives [7]. Diabetic complications often result in motor disabilities with depressive symptoms [8], and the chronicity of the condition frustrates the individual, as it weakens its strength and reduces its mental strength, resulting in adverse health effects, and non compliance to therapy [9, 10]. On the other hand, adaptation to illness is often accompanied by a variety of negative emotional reactions such as anger, guilt, disappointment, denial and loneliness $[9,11]$.

Diabetes, as well as cardiovascular diseases, asthma and hypertension is classified under chronic diseases [12-14]. Therefore, diabetes management requires integrated care and advanced access to it. Dynamic empowerment with a specific focus on maintaining a person's health, prevention and proper management without relapse to chronic diseases, is considered to be necessary [15-17].

In order to accelerate this kind of benefit transition for more than 133 million people living with a chronic disease [18], which represented $70 \%$ of the reported deaths worldwide in 1998, the Improving Chronic Illness care program created the Chronic Care Model which aimed at empowering health care improvements at the community, organization, practice and patient levels $[19,20]$.

The Chronic Care Model introduced well-documented concepts of change, combining the promotion of productive interactions between well-informed patients who take an active role in their care and resource management under the expert guidance of health care providers [21-23]. The Chronic Care Model (CCM) is promoted as a guide to improve chronic care and to realise patient-centred care in which problems such as fragmentation, guideline non-adherence, and restricted selfmanagement are limited [22]. Patient Assessment of
Chronic Illness Care (PACIC+) questionnaire has been developed, translated and applied internationally to patients with chronic diseases such as diabetes, hypertension, cardiovascular diseases and asthma [21, 24-33]. The Patient Assessment of Chronic Illness Care $(\mathrm{PACIC}+)$ measures the extent of alignment of chronic care with the CCM, and measures patients' chronic care experience. The model promotes the reconstruction of health care within the aim of continuous, coordinated and multi-sided care through health system [22, 34].

Poor management and control of diabetes often leads to poor disease outcomes, including impaired healthrelated quality of life (HRQL) and health status [35-37]. A tool that assesses the physical, psychological and social well-being of the individuals offers a comprehensive picture of the impact of the disease on the individual, as opposed to physiological and clinical examinations, which usually only detect health problems [35]. In essence, HRQL's assessment completes the clinical evaluation, adding the important element of the subjective assessment of his/her physical and psychosocial health by the patient himself/herself. Therefore, the wide range of information received by a HRQL assessment can contribute (a) to a sound and in-depth knowledge of the physical and psychosocial effects of the disease, (b) to a better understanding of the causes that patients react differently to the same disease, and (c) to planning and implementing clinical interventions and services to address the health effects of illnesses [38-40].

Various QoL assessment questionnaires have been developed for the DM in particular, but they are either too extensive and lack in application specificity [18], or are not susceptible to the generalization of their findings. The Short Form- 36 (SF-36) questionnaire, which is a general questionnaire, evaluates the physical and mental health of the individual, by using 8 scales: physical functioning (PF), role physical (RP), bodily pain (BP), general health $(\mathrm{GH})$, vitality (VT), social functioning (SF), role emotional (RE), and mental health $(\mathrm{MH})$. SF-36 is characterized by reliability and validity and is one of the most widely used tools for measuring QoL [41].

The SF-36 is widely accepted as one of the most commonly used general health measure in QoL with an obvious degree of reliability and validity. One of its most important features is that it provides age-matched and sex-matched population normative data [42].

Regarding the diabetes-specific measures, such as ADDQoL and DQoL and ADS, the latter is known to acquire valuable traits such as validity and comprehensiveness in terms of scoring. The first two diabetes specific measures, ADDQoL and DQoL, have been tested numerous times and present an increased degree of validity and reliability compared to ADS. However, issues in terms of feasibility constitute them unattractive for use 
in clinical settings. Finally, the DQoL includes several extra questions resulting in a rather lengthy form of questionnaire with enhanced complexity in terms of its opening questions that potentially could affect choices on the remaining items [42].

As far as CES-D scale is concerned its items are associated with depression and it has presented high degree of reliability when assessing the number, types and duration of depressive symptoms across racial, gender and age categories [43-45] with additional high internal consistency since Cronbach's coefficients range from .85 to .90 across studies [43].

The purpose of this study was to correlate PACIC+ and the revised 5As "ask, advise, agree, assist and arrange" scoring for a sample of DM patients with their QoL, depressive symptomatology, demographic and disease characteristics, self-management behaviours of healthy eating and physical activity.

\section{Methods}

The research questions of the study at hand are the following:

How do PACIC and 5As scores correlate to 1) patient characteristics, 2) self-management behaviours of healthy eating and physical activity?

How do PACIC and 5As scores correlate to patients with DM, QoL or depressive symptomatology.

\section{Participants}

The study comprised of 90 adult patients treated at a Public General Hospital of the city of Volos in Central Greece who were recently diagnosed (the last 6 months) with type I and type II DM.

\section{Procedure}

The study population consisted of a convenience sample of 90 patients with DM. The research was conducted between January and April 2018, in Volos Greece. Exclusion criteria included the inability of the patients to respond to the questionnaires due to the severity of their state of health. Patients with DM from the Intensive Care Unit, the Operating Room and the Emergency Department were excluded. Following the approval of the scientific council of the hospital, the self- completed questionnaires were distributed. All potential participants were instructed that the study was voluntary and confidential.

\section{Measures}

The questionnaire included demographics, data on the disease of DM, and the scales of PACIC+, the CES-D and SF-36. PACIC+ is a reliable, psychometrically tested for Greek patients instrument to measure the chronic care management experiences of patients. It has five subscales: 1) Patient activation (3 items), 2) Delivery system design/Decision support (3 items), 3) Goal setting (5 items), 4) Problem solving/Contextual counselling (4 items), and 5) Follow-up/Coordination (5 items) [20, 21]. Six additional questions are included in this $5 \mathrm{As}$ model questionnaire to enhance the rating of its scales. 5 As is a behavioral counseling model based on the scales of appraisal / appraise-advise-agree-help-organize and conform to the Chronic Care Model. Response categories in 20 questions range from 1 'almost never' to 5 'almost always', with higher scores indicating a higher extent to which patients received integrated care. The reliability was assessed and Cronbach alpha was found to be 0.913 . In order to compare QoL of DM patients our research team used the SF-36 questionnaire.

The SF-36 comprises of 36 questions that measure eight dimensions of health: physical functioning (PF), role physical (RP), bodily pain (BP), general health $(\mathrm{GH})$, vitality (VT), social functioning (SF), role emotional $(\mathrm{RE})$, and mental health $(\mathrm{MH})$. In addition to dimension scores, two summary scales (the Physical Components Summary [PCS] and the Mental Components Summary [MCS]) can be derived from the scales [46]. These two subscales with 8 items each, are scored from 0 to 100 with higher scores indicating higher levels of functioning. The reliability was assessed and Cronbach alpha was found to be 0.532 .

As depression has been presented in several studies as a potential confounder factor of QoL and of satisfaction with care in most chronic disease patients, including DM patients, we used the CES-D scale in order to assess the depressive symptomatology of DM patients. Our research took also into account that depression has been widely presented as an independent predictor of mortality in many chronic diseases [43, 47, 48]. The CES-D scale is a short self-report scale designed to measure depressive symptomatology in the general population, including 20 questions trying to investigate depressed mood, loss of pleasure and interest, weight loss / decreased appetite, insomnia, psychomotor vigilance or deceleration, fatigue and decreased energy, low self-esteem and concentration disorder, including two additional questions specifically aimed at investigating suicidal behavior. CES-D total scores range from 0 to 60 , with higher scores indicating more severe symptomatology. The reliability was tested by assessing the internal consistency which resulted in an overall Cronbach alpha of 0.887 .

\section{Data analysis}

Descriptive analysis was applied to describe the baseline characteristics of the study population. Continuous variables are presented as mean \pm standard deviation, while 
qualitative variables as absolute and relative frequencies (\%). Normal distribution of variables was tested with the Shapiro-Wilk test. Pearson chi squared and fisher exact test was used in correlating categorical variables. Pearson correlation coefficient was used for the association of score measurements. Tests were 2-sided and the statistically significant level was $\alpha=0.05$. Missing values were excluded from the analysis. Analysis conducted using SPSS v19.

\section{Results}

The 90 subjects of the sample who suffered from diabetes mellitus (Type II 64.4\%) were $52.8 \pm 21.2$ years old. Table 1 presents the relative frequency (\%) for two major types of diabetes together with other categorical data.

Physical activity was low for $50 \%(n=45)$ of participants and high for the remaining $50 \%(n=45)$. Most of them are non-smokers $60 \%(n=54), 18.9 \%(n=17)$ are ex-smokers and $18.9 \%(n=17)$ smokers. Associated diseases are reported in $38.9 \%(n=35)$ of the participants, while $57.8 \%(n=52)$ was on balanced diet. $61.1 \%(n=55)$ of the participants were diagnosed with diabetes in a random checkup. 51.1\% $(n=46)$ of them were treated with diet, $54.4 \%(n=49)$ used insulin injections, $48.9 \%$ $(n=44)$ peros medication and $25.6 \%(n=23)$ were treated with physical activity. PACIC+ scale scores were in similar level in all PACIC subscales (mean score range: $3.1-3.7$ ). The mean summary score on the PACIC was 3.3 of a possible 5 . 5as scoring: The mean for the overall 5As summary score was 3.1 of a possible 5 . $27.2 \%$ of the participants had a mean score of CES-D

Table 1 Demographics of the sample

\begin{tabular}{|c|c|c|}
\hline & $(N)$ & $\%$ \\
\hline Gender & (90) & \\
\hline Men & (35) & 38.9 \\
\hline Citizenship & (90) & \\
\hline Greek & (80) & 88.9 \\
\hline Marital status & (90) & \\
\hline Married & (55) & 61.1 \\
\hline Education & (86) & \\
\hline Compulsory & & 39.5 \\
\hline Secondary & & 23.3 \\
\hline Higher & & 37.2 \\
\hline Employment Status & (85) & \\
\hline Employed & & 49.4 \\
\hline Unemployed & & 15.3 \\
\hline Retired & & 35.3 \\
\hline Income & (86) & \\
\hline$<10.000 €$ & (47) & 54.7 \\
\hline
\end{tabular}

14.9 (SD \pm 11.1$)$. SF -36 scale scores were in a wider range (mean score: 40.6-74).

Multiple linear regression (stepwise method) with dependent variable the PACIC+ scale and independent variables demographic characteristics and CES-D scale revealed that eating habits, nationality and depression score were found to correlate independently with PACIC score (Table 2). More specifically participants who had a healthy diet scored 0.46 units higher in PACIC+ indicating better care received compared to participants who did not have healthy diet. Participants with nationality other than Greek scored 0.57 units lower in PACIC+ than those with Greek nationality and those with more depressive symptoms scored lower in PACIC+.

Multiple linear regression (stepwise method) with dependent variable the Physical Component Summary (PCS) and independent variables demographic characteristics and CES-D scale revealed that age, co-morbidity, and depression score were found to correlate independently with Physical Component Summary. More specifically older participants scored lower in Physical Component Summary, Participants with co-morbidity scored 6.60 units lower than those with no co-morbidity according to the Physical Component Summary. Participants with more depressive symptoms their physical health is deteriorating.

Table 2 Multiple linear regression (stepwise method) $(N=90)$

Multiple linear regression (stepwise method) with dependent variable the PACIC+ scale and independent variables demographic characteristics and CES-D scale $(N=90)$

$\begin{array}{lllll} & & \text { Coeff. }^{\mathbf{a}} & \text { SE }^{\mathbf{b}} & \mathbf{P} \\ \text { Healthy diet } & \text { no (reference cat) } & & & \\ & \text { yes/ sometimes } & 0.46 & 0.18 & \mathbf{0 . 0 1 3} \\ \text { Nationality } & \text { Greek (reference cat) } & & & \\ & \text { Other } & -0.57 & 0.21 & \mathbf{0 . 0 1 0} \\ \text { (CES-D) } & & -0.01 & 0.01 & \mathbf{0 . 0 2 7}\end{array}$

Multiple linear regression (stepwise method) with dependent variable the Physical Component Summary (PCS) and independent variables demographic characteristics and CES-D scale $(N=90)$

Age

$-0.29 \quad 0.07<0.001$

Co-morbidity no (reference cat)

$\begin{array}{lllll} & \text { Yes } & -6.60 & 2.47 & \mathbf{0 . 0 0 9} \\ \text { CES-D } & & -0.23 & 0.09 & \mathbf{0 . 0 1 0}\end{array}$

Multiple linear regression (stepwise method) with dependent variable the Mental Component Summary (MCS) and independent variables demographic characteristics and CES-D scale $(N=90)$

\begin{tabular}{|c|c|c|c|c|}
\hline \multicolumn{2}{|l|}{ Age } & -0.09 & 0.04 & 0.017 \\
\hline \multirow[t]{3}{*}{ Physical activity } & low (reference cat) & & & \\
\hline & Medium & 3.78 & 1.68 & 0.027 \\
\hline & High & 3.73 & 2.59 & 0.154 \\
\hline CES-D & & -0.55 & 0.07 & $<0.001$ \\
\hline
\end{tabular}


Multiple linear regression (stepwise method) with dependent variable the Mental Component Summary (MCS) and independent variables the demographic characteristics and the CES-D scale, revealed that age, physical activity and depression score were found to correlate independently with Mental Component Summary (Table 2). More specifically older participants scored lower in Mental Component Summary. Participants with medium physical activity scored 3.78 units higher in Mental Component Summary, hence they present better mental health compared with participants with low activity. Participants with more depressive symptoms present an overall worsening of their mental health.

Physical functioning was evaluated in the lower mean score (40.6), while bodily pain in the higher score (74). SF - 36 and PACIC+ scale scores (Table 3) show a positive and low correlation in several subscales. The total score of PACIC+ scale as well as the Patient activation score correlate significantly with vitality. More specifically both scores increased in higher scores of vitality $(p=0.034$ \& $p=0.028$ respectively). Delivery System / Practice Design score was increased in higher scores of mental health $(p=$ $0.01)$ and MCS $(p=0.03)$. Follow-up/ Coordination was increased in higher scores of bodily pain $(p=0.01)$, vitality $(p=0.002)$, social functioning $(p=0.028)$, mental health $(p=0.024)$ and MCS $(p=0.004)$.
Depression score (CES - D scale) was negatively correlated with several PACIC+ scale scores (Table 4). Higher depression mean score lead to lower PACIC+ summary score $(p=0.012)$, patient activation score $(p=$ 0.046), Delivery System / Practice Design score $(p=0.036)$ and mean Follow-up/ Coordination score $(p=0.001)$.

\section{Discussion}

Our findings demonstrate that almost $40 \%$ of our chronic diabetes patients co-suffered with hypertension, in agreement to previous studies which proved diabetes was associated with an increased risk of vascular complications, which leads to a decrease in QoL (eg hypertension, blindness, renal insufficiency / need for hemodialysis, limb rash, limb amputation, etc.) [49-55]. This study also revealed that one third of the participants suffered from mild depression, in agreement with previous findings of relevant studies, which reported important mental and emotional effects of diabetes patients [10] and strong correlation between symptoms of depression and diabetes $[8,56-60]$. Cramm \& Nieboer [24] have presented more often occurring depressive symptoms are associated with lower PACIC+ scores.

In the study at hand eating habits, nationality and depression scores were found to correlate independently

Table 3 SF -36 and PACIC+ scale scoring $(N=90)$

\begin{tabular}{|c|c|c|c|c|c|c|c|}
\hline \multirow[b]{2}{*}{ Physical functioning } & \multicolumn{2}{|c|}{$\begin{array}{l}\text { PACIC+ } \\
\text { summary }\end{array}$} & \multirow{2}{*}{$\begin{array}{l}\text { Patient } \\
\text { activation } \\
0.12\end{array}$} & \multirow{2}{*}{$\begin{array}{l}\text { Delivery System } \\
\text { design/Decision support } \\
-0.09\end{array}$} & \multirow{2}{*}{$\begin{array}{l}\text { Goal } \\
\text { Setting } \\
0.02\end{array}$} & \multirow{2}{*}{$\begin{array}{l}\text { Problem Solving/ } \\
\text { Contextual counselling } \\
0.08\end{array}$} & \multirow{2}{*}{$\begin{array}{l}\text { Follow-up/ } \\
\text { Coordination } \\
0.12\end{array}$} \\
\hline & $r$ & 0.07 & & & & & \\
\hline & $p$ & 0.508 & 0.255 & 0.429 & 0.877 & 0.443 & 0.276 \\
\hline \multirow[t]{2}{*}{ Role Physical } & r & 0.01 & 0.04 & -0.04 & -0.03 & 0.01 & 0.05 \\
\hline & $p$ & 0.923 & 0.708 & 0.743 & 0.765 & 0.940 & 0.621 \\
\hline \multirow[t]{2}{*}{ Bodily pain } & r & 0.11 & 0.09 & -0.06 & 0.06 & 0.01 & 0.27 \\
\hline & $p$ & 0.322 & 0.394 & 0.597 & 0.550 & 0.945 & 0.010 \\
\hline \multirow[t]{2}{*}{ General health } & r & 0.20 & 0.17 & 0.14 & 0.13 & 0.18 & 0.19 \\
\hline & $p$ & 0.064 & 0.118 & 0.204 & 0.235 & 0.087 & 0.070 \\
\hline \multirow[t]{2}{*}{ Vitality } & r & 0.23 & 0.23 & 0.10 & 0.08 & 0.18 & 0.32 \\
\hline & $p$ & 0.034 & 0.028 & 0.358 & 0.466 & 0.088 & 0.002 \\
\hline \multirow[t]{2}{*}{ Social functioning } & r & 0.20 & 0.14 & 0.12 & 0.12 & 0.17 & 0.23 \\
\hline & $p$ & 0.064 & 0.202 & 0.278 & 0.246 & 0.104 & 0.028 \\
\hline \multirow[t]{2}{*}{ Role Emotional } & r & 0.01 & 0.01 & -0.06 & -0.05 & -0.01 & 0.13 \\
\hline & $p$ & 0.929 & 0.941 & 0.560 & 0.624 & 0.896 & 0.222 \\
\hline \multirow[t]{2}{*}{ Mental health } & r & 0.19 & 0.16 & 0.27 & 0.07 & 0.11 & 0.24 \\
\hline & $p$ & 0.069 & 0.137 & 0.010 & 0.517 & 0.297 & 0.024 \\
\hline \multirow[t]{2}{*}{ PCS } & r & 0.12 & 0.09 & -0.04 & 0.10 & 0.13 & 0.15 \\
\hline & $p$ & 0.280 & 0.402 & 0.749 & 0.396 & 0.240 & 0.175 \\
\hline \multirow[t]{2}{*}{ MCS } & r & 0.20 & 0.11 & 0.24 & 0.03 & 0.14 & 0.31 \\
\hline & $p$ & 0.075 & 0.327 & 0.030 & 0.766 & 0.202 & 0.004 \\
\hline
\end{tabular}


Table 4 PACIC+ and CES - D $(N=90)$

\begin{tabular}{|c|c|c|}
\hline & & CES-D \\
\hline \multirow[t]{2}{*}{ PACIC+ summary } & r & -0.27 \\
\hline & $p$ & 0.012 \\
\hline \multirow[t]{2}{*}{ Patient activation } & r & -0.21 \\
\hline & $p$ & 0.046 \\
\hline \multirow[t]{2}{*}{ Delivery System Design/ Decision Support } & r & -0.23 \\
\hline & $p$ & 0.035 \\
\hline \multirow[t]{2}{*}{ Goal Setting } & r & -0.16 \\
\hline & $\mathrm{p}$ & 0.142 \\
\hline \multirow[t]{2}{*}{ Problem Solving/ Contextual counselling } & r & -0.15 \\
\hline & $p$ & 0.170 \\
\hline \multirow[t]{2}{*}{ Follow-up/ Coordination } & r & -0.36 \\
\hline & $\mathrm{p}$ & 0.001 \\
\hline
\end{tabular}

with PACIC+ score. Glasgow and colleagues were not able to demonstrate significant differences in PACIC+ scores regarding patients' sociodemographic characteristics within their particular research setting in the United State of America [20, 21]. However, Rosemann and colleagues managed to identify significant differences on the basis of age, education and psychiatric symptoms in specific European health care facilities [25].

In Cramm's and Nieboer's study there were specific categories of the sample, such as the young and less depressed patients which aligned with higher PACIC+ scores, and therefore verifying that their care is closely associated with the CCM [24]. However, the two studies (Cramm-Nieboer and Rosemann and colleagues) differ on how education is related to PACIC+ scores. On the one hand Rosemann and colleagues' findings present a significant relation between education and PACIC+ scores, while Cramm's and Nieboer's study showed no significant relation exists between the aforementioned. This difference may be explained by the duration of the disease. Unlike Rosemann's and colleagues study in which patients had been suffering from osteoarthritis for over 14 years, Cramm's and Nieboer's patients were only recently diagnosed [24, 29].

The finding that younger and less distressed patients are more likely to report high PACIC+ scores may also indicate differences in physicians' actions towards different groups of patients, and that these patients pursue CCM-compliant treatment more aggressively. However, this correlation is non-conclusive. However, this specific insight is useful in any case, because it implies that ensuring that all groups of patients benefit equally from any improvements in treating chronic diseases is an important feature in implementing CCM [24].

In addition this study showed that participants who followed a balanced diet experienced a better overall care than those who did not. They also received better care with regard to the dimensions of patient activation, the design of the decision support system, as well as monitoring, coordination and feedback.

Mean values of subscales of the PACIC+ questionnaire show that participants reported relatively moderate levels of satisfaction for the diabetes care. The lowest mean value was found in the goal setting subscale, which was slightly above the middle of the scale, followed by the patient's activation subscale. The mean values of all subscales varied to similar levels to a previous conducted survey in Colorado on 363 Type II diabetic patients, as the target setting subscale received the lowest score and was related to the monitoring, coordination and feedback subscale, suggesting that they were almost similar to the Model of Chronic Care [21], which varied at a relatively modest level. This could be explained by the fact that health care systems had already included model elements in their day-to-day clinical practice through choice of approach and will or by the specificity of diabetic patients which comply more to the Chronic Care Model [61], with demands in their care for both dietary habits and education for medication.

Therefore, care provided to diabetic patients should take into account their need to be aware of the clear goals of the treatment. It should also involve them in the healing process, which will contribute to their further activation. Monitoring of care, coordination and feedback, reflect the communication deficit and management of the disease. There is a problem-solving subscale with specialized counseling which should be taken seriously into account by specialists taking care of DM patients.

Finally, the highest mean value was received by the Delivery System design/Decision support of the care system, which means that despite the above results patients still believe that caring system effectively supports them. Several studies have occasionally addressed satisfaction with the treatment of diabetic patients [52-54] in order to finally fulfill the ultimate goal of improving the quality of the treatment provided.

Our research revealed lowest mean value for the dimensions of SF-36, referring to the physical role and general health. Interestingly, the mean value of PCS score was lower than the mean of the corresponding MCS, suggesting that the participants experienced more physical than mental burden on their health. However, mental and physical health values remain at low levels that require improvement. In our study, age, suffering from other disease and depression score, were found to correlate independently with Physical Component Summary, while age, physical activity and depression with the Mental Component Summary. Diabetes impacts QoL immensely [62, 63] and has intense effects on the incidence of depression [64], a rather important feature of comorbidity in most chronic diseases. Several studies have presented the 
negative effects of depression on a patient's ability to fulfil its self-management skills [65] and therefore depression may as well contribute to a rather poor attitude towards his/her efforts to glycaemic control $[65,66]$.

In addition, our study results showed that there have been significant positive correlations between several dimensions of care received and QoL, which agree with the main positions of the Chronic Care Model. Specifically, more vitality was correlated with more care and patient activation. Furthermore, higher mental health rates were correlated with considerably higher rates in the design of the care system with decision support, and higher values in the dimensions of physical pain, vitality, social role and mental health were correlated with higher values in the care dimension that includes monitoring, coordination and feedback. Findings from other studies are controversial with Cramm \& Nieboer [24] suggesting that QoL could not be predicted by PACIC+ ratings and implying that the severity of the chronic disorder itself cannot be control by the care provided to chronically ill patients, However, in a study from Great Britain, lower scores of SF-36 were associated with the greater burden of diabetes caring [67]. Results from another study about improving care for diabetes patients indicated that SF36's Physical Component Summary (PCS) and Mental Component Summary (MCS) scores for diabetes patients were substantially lower than the diabetes-free individuals [68].

In the limitations of the study it should be mentioned that the sample comes from a single healthcare service so we cannot claim to have a representation of all Greek healthcare organizations. In addition, the findings of this study are limited to a population that resides in a particular geographical area and refers to a disease with perhaps different approaches in terms of treatment. Another limitation could be the use of SF-36 as a measure of Qol and not a diabetes-specific measure, such as ADDQoL and DQoL and ADS which were not available and issues in terms of feasibility, complexity and length make them unattractive for use.

\section{Conclusions}

This study presented important insights to the DM patients' perception of the health services they receive. It concluded that the care provided to diabetic patients should take into account their need to be aware of the clear goals of the treatment. That is why patients should be involved more closely in the healing process, which will contribute to their further activation in the management of the disease. Despite the fact that DM patients believe that the caring system effectively supports them, the design of Delivery System /Decision support of the care system, should be improved.

\section{Abbreviations}

PACIC+: Patient Assessment of Chronic Illness Care plus; PACIC: Patient Assessment of Chronic Illness Care; SF-36: The Short Form (36) Health Survey; QoL: Quality of life; DDQoL: Diabetes-dependent QoL; DQoL: Diabetes QoL; ADS: Appraisal of Diabetes Scale; CES-D: Center for Epidemiologic Studies Depression Scale; SPSS: Statistical Package for the Social Sciences;

DM: Diabetes mellitus; SD: Standard deviation; HbA1c: Glycated hemoglobin; HRQL: Health Related QoL; PF: Physical functioning; RP: Role physical; BP: Bodily pain; GH: General health; VT: Vitality; SF: Social functioning; RE: Role emotional; MH: Mental health; CCM: The Chronic Care Model; WHO: World Health Organization; PCS: Physical Components Summary; MCS: Mental Components Summary

\section{Acknowledgements}

Not applicable.

\section{Authors' contributions}

PS and EK conceived of the originally presented idea while CD and EL performed the computations, carried out the research by distributing, collecting the questionnaires' and SK and TP statistically analyzed the questionnaires' results, CD and MM wrote the manuscript and AN substantially revised it. The author(s) read and approved the final manuscript.

Funding

Not applicable.

\section{Availability of data and materials}

The datasets generated and analyzed during the current study are not publicly available to preserve the privacy of the participants but are available from the corresponding author on reasonable request.

\section{Ethics approval and consent to participate}

This study was approved by the Ethics Committee of the General Public Hospital of Volos "Achillopouleio" and its Board of Directors gave permission for conducting the survey (4/19-3-2018). Written informed consent was obtained. Both of the aforementioned are available to be translated from Greek.

\section{Consent for publication}

Not applicable.

\section{Competing interests}

The authors declare that they have no competing interests.

\section{Author details}

'Department of Nursing, University of Thessaly, Perifreiakh Odos Larisas, Trikalon, TK 41110 Larisa, Greece. ${ }^{2}$ General Public Hospital of Volos "Achillopouleio", Athanasaki 3, TK 38222 Volos, Greece. ${ }^{3}$ University of Thessaly, Perifreiakh Odos Larisas, Trikalon, TK 41110 Larisa, Greece. ${ }^{4}$ Hellenic Open University, Parodos Artistotelous 18, TK 26335 Patras, Greece. ${ }^{5}$ Department of Nursing, Cyprus University of Technology, 30 Archbishop Street, 3036 Limassol, Cyprus.

Received: 20 May 2019 Accepted: 4 June 2020

Published online: 16 June 2020

\section{References}

1. American Diabetes A. Diagnosis and classification of diabetes mellitus. Diabetes Care. 2010;33(Suppl 1):S62-S9.

2. Makrylakis K. Pathophysiology of type 2 diabetes mellitus (in Greek). In: Katsilambros N, Diakoumopoulou E, loannidis I, Liatis S, Makrilakis K, Tentolouris N, et al., editors. Diabetes mellitus in clinical practice. Athens: Litsas Medical Publications; 2005. p. 49-63.

3. Tentolouris N. General diabetes (in Greek). In: Katsilambros N, Diakoumopoulou E, loannidis I, Liatis S, Makrilakis K, Tentolouris N, et al., editors. Questions and answers on diabetes mellitus (diabetes from A to Z). Athens: Litsas Medical Publications; 2005. p. 7-28.

4. Saeedi P, Petersohn I, Salpea P, Malanda B, Karuranga S, Unwin S, Colagiuri S, Guariguata L, Motala AA, Ogurtsova K, Shaw J, Bright D, Williams R. Global and regional diabetes prevalence estimates for 2019 and projections for 
2030 and 2045: Results from the International Diabetes Federation Diabetes Atlas, $9^{\text {th }}$.edition. Diabetes Res Clin Pract. 2019;157:107843.

5. Liatis S, Dafoulas GE, Kani C, Politi A, Litsa P, Sfikakis PP, et al. The prevalence and treatment patterns of diabetes in the Greek population based on realworld data from the nation-wide prescription database. Diabetes Res Clin Pract. 2016;118:162-7.

6. Pitta R, Grigoriadou E, Marina E, Kouvatsou Z, Didaggelos T, Karamitsos D. Quality of life and diabetes mellitus (in Greek). Greek Diabetological Chronicles. 2006;4(19):282-94.

7. Tachtsoglou K, Eliades X. Effects of diabetes on the quality of life of patients. Perioper Nurs. 2015;4:50-7.

8. Holt Rl, de Groot M, Golden SH. Diabetes and depression. Curr Diabetes Rep. 2014;14(6):491.

9. Gregg EW, Beckles GL, Williamson DF, Leveille SG, Langlois JA, Engelgau MM, et al. Diabetes and physical disability among older U.S. adults. Diabetes Care. 2000;23(9):1272-7.

10. Wong E, Backholer K, Harding J, Gearon E, Stevenson C, Freak-Poli R, et al. A systematic review and meta-analysis of diabetes and risk of physical disability and functional impairment - protocol. Syst Rev. 2012;1:47.

11. Zhang X, Norris SL, Chowdhury FM, Gregg EW, Zhang P. The effects of interventions on health-related quality of life among persons with diabetes: a systematic review. Med Care. 2007:45(9):820-34.

12. Kenny SJ, Smith PJ, Goldschmid MG, Newman JM, Herman WH. Survey of physician practice behaviors related to diabetes mellitus in the U.S. Physician adherence to consensus recommendations. Diabetes Care. 1993; 16(11):1507-10

13. Perrin JM, Homer CJ, Berwick DM, Woolf AD, Freeman JL, Wennberg JE. Variations in rates of hospitalization of children in three urban communities. N Engl J Med. 1989;320(18):1183-7.

14. Stockwell DH, Madhavan S, Cohen H, Gibson G, Alderman MH. The determinants of hypertension awareness, treatment, and control in an insured population. Am J Public Health. 1994:84(11):1768-74.

15. Calkins E, Boult C, Wagner EH, Pacala J. New ways to care for older people: building systems based on evidence. New York: Springer; 1999.

16. Wagner EH, Austin BT, Von Korff M. Improving outcomes in chronic illness Manag Care Q. 1996:4(2):12-25.

17. Wagner EH, Austin BT, Von Korff M. Organizing care for patients with chronic illness. Milbank Q. 1996;74(4):511-44.

18. Bodenheimer T, Chen E, Bennett HD. Confronting the growing burden of chronic disease: can the U.S. health care workforce do the job? Health Aff (Project Hope). 2009;28(1):64-74.

19. Coleman K, Austin BT, Brach C, Wagner EH. Evidence on the chronic care model in the new millennium. Health Aff (Project Hope). 2009;28(1):75-85.

20. Glasgow RE, Wagner EH, Schaefer J, Mahoney LD, Reid RJ, Greene SM. Development and validation of the Patient Assessment of Chronic Illness Care (PACIC). Med Care. 2005;43(5):436-44.

21. Glasgow RE, Whitesides H, Nelson CC, King DK. Use of the Patient Assessment of Chronic Illness Care (PACIC) with diabetic patients: relationship to patient characteristics, receipt of care, and self-management. Diabetes Care. 2005;28(11):2655-61

22. Wagner EH, Austin BT, Davis C, Hindmarsh M, Schaefer J, Bonomi A Improving chronic illness care: translating evidence into action. Health Aff (Project Hope). 2001;20(6):64-78.

23. Wagner EH. Chronic disease management: what will it take to improve care for chronic illness? Eff Clin Pract. 1998;1(1):2-4.

24. Cramm JM, Nieboer AP. The chronic care model: congruency and predictors among patients with cardiovascular diseases and chronic obstructive pulmonary disease in the Netherlands. BMC Health Serv Res. 2012;12:242.

25. Drewes HW, de Jong-van Til JT, Struijs JN, Baan CA, Tekle FB, Meijboom BR, et al. Measuring chronic care management experience of patients with diabetes: PACIC and PACIC+ validation. Int J Integr Care. 2012;12:e194.

26. Goetz K, Freund T, Gensichen J, Miksch A, Szecsenyi J, Steinhaeuser J. Adaptation and psychometric properties of the PACIC short form. Am J Manag Care. 2012;18(2):e55-60.

27. Maindal HT, Sokolowski I, Vedsted P. Adaptation, data quality and confirmatory factor analysis of the Danish version of the PACIC questionnaire. Eur J Pub Health. 2012;22(1):31-6.

28. Rick J, Rowe K, Hann M, Sibbald B, Reeves D, Roland M, et al. Psychometric properties of the Patient Assessment Of Chronic Illness Care measure: acceptability, reliability and validity in United Kingdom patients with longterm conditions. BMC Health Serv Res. 2012;12:293.
29. Rosemann T, Laux G, Droesemeyer S, Gensichen J, Szecsenyi J. Evaluation of a culturally adapted German version of the Patient Assessment of Chronic Illness Care (PACIC 5A) questionnaire in a sample of osteoarthritis patients. J Eval Clin Pract. 2007:13(5):806-13.

30. Schmittdiel J, Mosen DM, Glasgow RE, Hibbard J, Remmers C, Bellows J. Patient Assessment of Chronic Illness Care (PACIC) and improved patientcentered outcomes for chronic conditions. J Gen Intern Med. 2008;23(1):77-80.

31. Aragones A, Schaefer EW, Stevens D, Gourevitch MN, Glasgow RE, Shah NR. Validation of the Spanish translation of the Patient Assessment of Chronic Illness Care (PACIC) survey. Prev Chronic Dis. 2008;5(4):A113.

32. Taggart J, Chan B, Jayasinghe UW, Christl B, Proudfoot J, Crookes P, et al. Patients Assessment of Chronic IIIness Care (PACIC) in two Australian studies: structure and utility. J Eval Clin Pract. 2011;17(2):215-21.

33. Wensing M, van Lieshout J, Jung HP, Hermsen J, Rosemann T. The Patients Assessment Chronic Illness Care (PACIC) questionnaire in the Netherlands: a validation study in rural general practice. BMC Health Serv Res. 2008;8:182.

34. Walters BH, Adams SA, Nieboer AP, Bal R. Disease management projects and the chronic care model in action: baseline qualitative research. BMC Health Serv Res. 2012;12(1):114.

35. Guyatt GH, Feeny DH, Patrick DL. Measuring health-related quality of life. Ann Intern Med. 1993;118(8):622-9.

36. Mackeigan LD, Pathak DS. Overview of health-related quality-of-life measures. Am J Hosp Pharm. 1992;49(9):2236-45.

37. Weinberger M, Kirkman MS, Samsa GP, Cowper PA, Shortliffe EA, Simel DL, et al. The relationship between glycemic control and health-related quality of life in patients with non-insulin-dependent diabetes mellitus. Med Care. 1994;32(12):1173-81.

38. Fontaine KR, Barofsky I. Obesity and health-related quality of life. Obes Rev. 2001;2(3):173-82

39. Theodoropoulou E, Karterolliotis K, Nassis G, Koskolou M, Geladas N Methods of assessing health-related quality of life kinesiology: humanistic division. 2012;5(1):58-66

40. Calaminus G, Barr R. Economic evaluation and health-related quality of life. Pediatr Blood Cancer. 2008;50(5 Suppl):1112-5.

41. El Achhab Y, Nejiari C, Chikri M, Lyoussi B. Disease-specific health-related quality of life instruments among adults diabetic: a systematic review. Diabetes Res Clin Pract. 2008:80(2):171-84.

42. Brazier JE, Harper R, Jones NM, O'Cathain A, Thomas KJ, Usherwood T, et al. Validating the SF-36 health survey questionnaire: new outcome measure for primary care. BMJ. 1992;305(6846):160-4.

43. Sawyer RL. The CES-D Scale: a self-report depression scale for research in the general population; 1977. p. 385-401.

44. Knight RG, Williams S, McGee R, Olaman S. Psychometric properties of the Centre for Epidemiologic Studies Depression Scale (CES-D) in a sample of women in middle life. Behav Res Ther. 1997;35(4):373-80. https://doi.org/10. 1016/s0005-7967(96)00107-6.

45. Roberts RE, Vernon SW, Rhoades HM. Effects of language and ethnic status on reliability and validity of the Center for Epidemiologic StudiesDepression Scale with psychiatric patients. J Nerv Ment Dis. 1989;177(10): 581-92. https://doi.org/10.1097/00005053-198910000-00001.

46. Xenouli G, Xenoulis K, Sarafis P, Niakas D, Alexopoulos EC. Validation of the World Health Organization Disability Assessment Schedule (WHO-DAS II) in Greek and its added value to the Short Form 36 (SF-36) in a sample of people with or without disabilities. Disabil Health J. 2016;9(3):518-23.

47. Lesperance F, Frasure-Smith N, Talajic M. Major depression before and after myocardial infarction: its nature and consequences. Psychosom Med. 1996; 58(2):99-110.

48. Morris P, Robinson R, Andrzejewski P, Samuels J, Price T. Association of depression with 10-year poststroke mortality. Am J Psychiatry. 1993;150(1): 124-9.

49. Frei A, Chmiel C, Schläpfer $H$, et al. The Chronic CARe for diAbeTes study (CARAT): a cluster randomized controlled trial. Cardiovasc Diabetol. 2010;9: 23. https://doi.org/10.1186/1475-2840-9-23.

50. Gensichen J, Muth C, Butzlaff M, Rosemann T, Raspe H, de Cornejo GM, Beyer M, Harter M, Muller UA, Angermann CE. The future is chronic: German primary care and the Chronic Care Model--The comprehensive principles in the proactive treatment of the chronically ill. Z Arztl Fortbild Qualitatssich. 2006;100(5):365-74.

51. Gerlach FM, Beyer M, Saal K, Peitz M, Gensichen J. New perspectives in the primary care of the chronically ill--against the "tyranny of the urgent". Part 2 
the chronic care model und case management as the basis of a forwardlooking approach to primary care. Z Arztl Fortbild Qualitatssich. 2006;100(5): 345-52.

52. Biderman A, Noff E, Harris SB, Friedman N, Levy A. Treatment satisfaction of diabetic patients: what are the contributing factors? Fam Pract. 2009;26(2): $102-8$.

53. Bradley C, Lewis KS. Measures of psychological well-being and treatment satisfaction developed from the responses of people with tablet-treated diabetes. Diabet Med. 1990;7(5):445-51.

54. Greenfield S, Kaplan SH, Kahn R, Ninomiya J, Griffith JL. Profiling care provided by different groups of physicians: effects of patient case-mix (bias) and physician-level clustering on quality assessment results. Ann Intern Med. 2002;136(2):111-21.

55. Dyck PJ, Kratz KM, Karnes JL, Litchy WJ, Klein R, Pach JM, et al. The prevalence by staged severity of various types of diabetic neuropathy, retinopathy, and nephropathy in a population-based cohort: the Rochester diabetic neuropathy study. Neurology. 1993;43(4):817-24.

56. Brown LC, Majumdar SR, Newman SC, Johnson JA. Type 2 diabetes does not increase risk of depression. CMAJ. 2006;175(1):42-6.

57. de Jonge P, Roy JF, Saz P, Marcos G, Lobo A. Prevalent and incident depression in community-dwelling elderly persons with diabetes mellitus: results from the ZARADEMP project. Diabetologia. 2006:49(11):2627-33.

58. Golden SH, Lee HB, Schreiner PJ, Diez Roux A, Fitzpatrick AL, Szklo M, et al. Depression and type 2 diabetes mellitus: the multiethnic study of atherosclerosis. Psychosom Med. 2007;69(6):529-36.

59. Maraldi C, Volpato S, Penninx BW, Yaffe K, Simonsick EM, Strotmeyer ES, et al. Diabetes mellitus, glycemic control, and incident depressive symptoms among 70- to 79-year-old persons: the health, aging, and body composition study. Arch Intern Med. 2007;167(11):1137-44.

60. Polsky D, Doshi JA, Marcus S, Oslin D, Rothbard A, Thomas N, et al. Longterm risk for depressive symptoms after a medical diagnosis. Arch Intern Med. 2005;165(11):1260-6.

61. Frei A, Senn O, Huber F, Vecellio M, Steurer J, Woitzek K, et al. Congruency of diabetes care with the chronic care model in different Swiss health care organisations from the patients' perspective: a cross sectional study. Swiss Med Wkly. 2014;144:W13992.

62. Anderson RM, Funnell MM. The art of empowerment: psychology in diabetes care; 2000.

63. Rubin RR, Peyrot M. Quality of life and diabetes. Diabetes Metab Res Rev. 1999;15(3):205-18. https://doi.org/10.1002/(SICl)1520-7560(199905/06)15:3< 205::AID-DMRR29>3.0.CO:2-O

64. Lustman PJ, Griffith LS, Clouse RE. Depression in adults with diabetes. Results of 5-yr follow-up study. Diabetes Care. 1988;11(8):605-12. https://doi. org/10.2337/diacare.11.8.605.

65. de Groot M, Jacobson AM, Samson JA, Welch G. Glycemic control and major depression in patients with type 1 and type 2 diabetes mellitus. Psychosom Res. 1999;46(5):425-35. https://doi.org/10.1016/S00223999(99)00014-8.

66. Anderson RJ, Freedland KE, Clouse RE, Lustman PJ. The prevalence of comorbid depression in adults with diabetes: a meta-analysis. Diabetes Care. 2001;24(6):1069-78. https://doi.org/10.2337/diacare.24.6.1069.

67. Woodcock AJ, Julious SA, Kinmonth AL, Campbell MJ. Problems with the performance of the SF-36 among people with type 2 diabetes in general practice. Qual Life Res. 2001;10:661-70.

68. Deaton C, Kimble LP, Veledar E, Hartigan P, Boden WE, O'Rourke R, et al. The synergistic effect of heart disease and diabetes on self-management, symptoms, and health status. Heart Lung. 2006;35:315-23.

\section{Publisher's Note}

Springer Nature remains neutral with regard to jurisdictional claims in published maps and institutional affiliations.

Ready to submit your research? Choose BMC and benefit from:

- fast, convenient online submission

- thorough peer review by experienced researchers in your field

- rapid publication on acceptance

- support for research data, including large and complex data types

- gold Open Access which fosters wider collaboration and increased citations

- maximum visibility for your research: over $100 \mathrm{M}$ website views per year

At $\mathrm{BMC}$, research is always in progress.

Learn more biomedcentral.com/submissions 